\title{
Investigating characteristics of organizational culture
}

\author{
Sanjar Salajeq $^{\mathrm{a}^{*}}$ and Ali Naderifar ${ }^{\mathrm{b}}$
}

${ }^{a}$ Assistant Professor, Department of Management, Kerman Branch, Islamic Azad University, Kerman, Iran

${ }^{b}$ Phd student, Department of Management, Kerman Branch, Islamic Azad University, Kerman, Iran

\section{H R O N I C L E}

\section{Article history:}

Received June 4, 2014

Accepted 8 October 2014

Available online

October 102014

Organizational culture

Denison model

Organizational framework

\section{A B S T R A C T}

Studying the behavior of members of a firm is considered as the primary step in understanding the organization's culture. In fact, it is always essential to study organizations' culture when a new action is about to occur. In fact, by leveraging culture, it is becoming easier to accomplish other tasks within organizations. This paper presents an empirical investigation to determine important factors influencing organizational culture in food industry. The proposed study has adapted a questionnaire based on Denison organizational culture dimensions and distributed it among different groups of employees who worked for one of Iranian food maker in city of Zahedan, Iran. Cronbach alphas for job involvement, consistency, compatibility and mission are $0.786,0.779,0.707$ and 0.908 , respectively. The results indicate that dimensions of job involvement (3.31) and organizational compatibility (3.16) are in better position compared with dimensions of consistency (3.14) and mission (3.11). The study does not find any significance difference between in internal-external focus. In other words, the organization has paid sufficient attention to internal as well as external affairs.

\section{Introduction}

Organizational culture plays an essential role on the success of business units and there are many evidences on positive correlation between organizational performance and organizational culture (Ashkanasy et al., 2000; Kinicki \& Kreitner, 2006). Several Japanese firms owe their success for having a high level of organizational culture and employee commitment (Mobley et al., 2005). Barbosa and Cabral-Cardoso (2007) investigated the way higher-education firms were reacting to the challenges of an increasingly diverse academic force and the extent to which organizational culture adapted and values diversity, thus permitting the university to take advantage from talented people with diverse backgrounds. They reported that the firm studied was failing to promote equal opportunities policies and also to manage the diverse academic workforce.

Henri (2006) investigated the relationships between organizational culture and the diversity of measurement and the nature of use. They found that top managers of firms reflecting a flexibility 
dominant type could use more performance measures and concentrate organizational attention, support strategic decision-making and legitimate actions to a bigger extent than top managers of firms reacting a control dominant kind. Kwantes and Boglarsky (2007) investigated perceptions of which characteristics of organizational culture were associated with leadership and personal effectiveness based on some data gathered from Canada, Hong Kong, New Zealand, South Africa, the United Kingdom, and the United States. They stated that organizational culture was strongly associated with both leadership effectiveness and personal effectiveness.

Philip and McKeown (2004) surveyed the contribution which anthropology could make in the study of organizational culture and more specifically, in examining the relationship between culture and business transformation. They believed that the cultural changes could yield a range of strategies such as the development of managerial and organizational competencies, information systems, and quality management practices. Tsui et al. (2006) reported on when and why decoupling between CEO leadership behavior and organizational culture occur. They presented directions for future research on both leadership and organizational culture phenomena and their potential relationships. Yilmaz and Ergun (2008) studied organizational culture and firm effectiveness by studying relative impacts of culture traits and the balanced culture hypothesis in an emerging economy.

This paper presents an empirical investigation to study to investigate organizational culture using Denison model. Denison model has extensively been used for different organization in various industry. Jofreh and Masoumi (2013), for instance, used this model in banking industry. Kia et al. (2013) used Denison model (Denison \& Mishra, 1995; Denison, 1996, 2000; Denison et al., 2006) and confirmed that there are strong relationships between knowledge management from one side and mission, consistency, involvement and adaptability. Denison model studies any organization in terms of four characteristics as follows,

External Focus (Adaptability + Mission): An organization with a strong external focus is concentrated on adapting and changing in response to the external environment. A strong external focus typically influences on revenue, sales growth, and market share.

Internal Focus (Involvement + Consistency): An organization with a strong internal focus is normally concentrated on the dynamics of the internal integration of systems, structures, and processes. A strong internal focus is associated with the higher levels of quality, fewer defects and less rework, good resource utilization, and high employee satisfaction.

Flexibility (Adaptability + Involvement): A flexible organization has the capability to make changes in response to the environment. Its aim is on the marketplace and its people. A flexible firm is typically linked to higher levels of product and service innovation, creativity, and a fast response to the changing requirements of customers and employees.

Stability (Mission + Consistency): A stable firm has the capacity to stay focused and predictable over time. A stable organization is associated with high return on assets, investments and sales, as well as strong business operations.

\section{The proposed study}

Denison model is a popular model for learning more about organizational culture. Fig.1 demonstrates details of Denison dimensions. The questionnaire includes of 60 questions in Likert scale and Cronbach alpha has been calculated as 0.927 , which is well about the acceptable limit. 


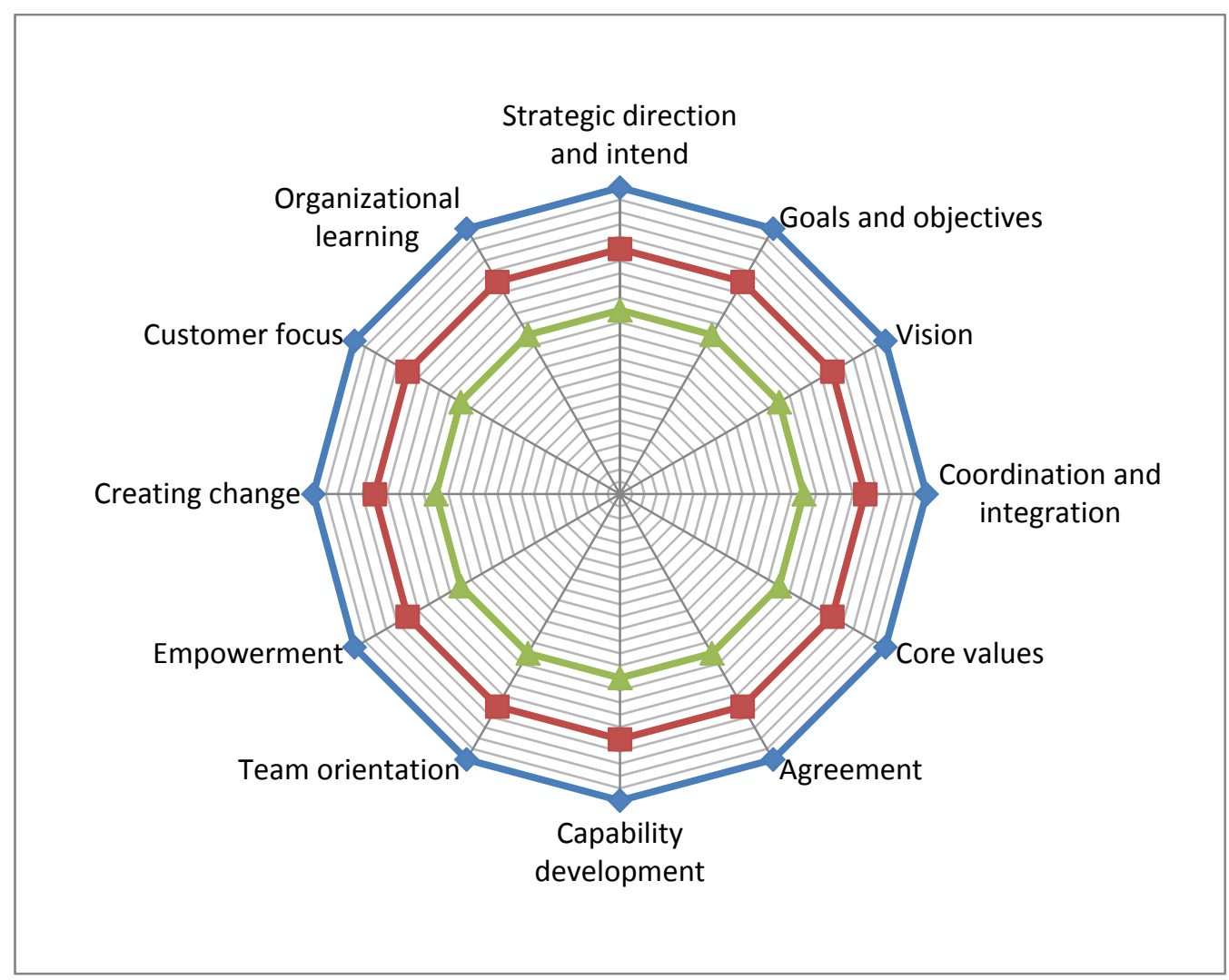

Fig. 1. The structure of Denison model

The proposed study of this paper uses Denison's standard questionnaire (Denison, 2000) to examine the following six questions,

1. What is the status of organizational culture in terms of job involvement?

2. What is the status of organizational culture in terms of consistency?

3. What is the status of organizational culture in terms of compatibility?

4. What is the status of organizational culture in terms of mission?

5. What sort of changes does organizational culture need in macro scale?

6. What is the relationship between the main dimensions and Denison model.

The study is executed among employees of a food maker named Ramshar located in city of Zahedan, Iran. The sample size is calculated as follows,

$n=\frac{N \times z_{\alpha / 2}^{2} \times p \times q}{\varepsilon^{2} \times(N-1)+z_{\alpha / 2}^{2} \times p \times q}$,

where $N$ is the population size, $p=1-q$ represents the yes/no categories, $z_{\alpha / 2}$ is CDF of normal distribution and finally $\varepsilon$ is the error term. Since we have $p=0.5, z_{\alpha / 2}=1.96$ and $N=177$, the number of sample size is calculated as $n=82$. Cronbach alphas for job involvement, consistency, compatibility and mission are $0.786,0.779,0.707$ and 0.908 , respectively. These values are within acceptable leves. In addition, Fig. 2 shows details of the mean of each component. 


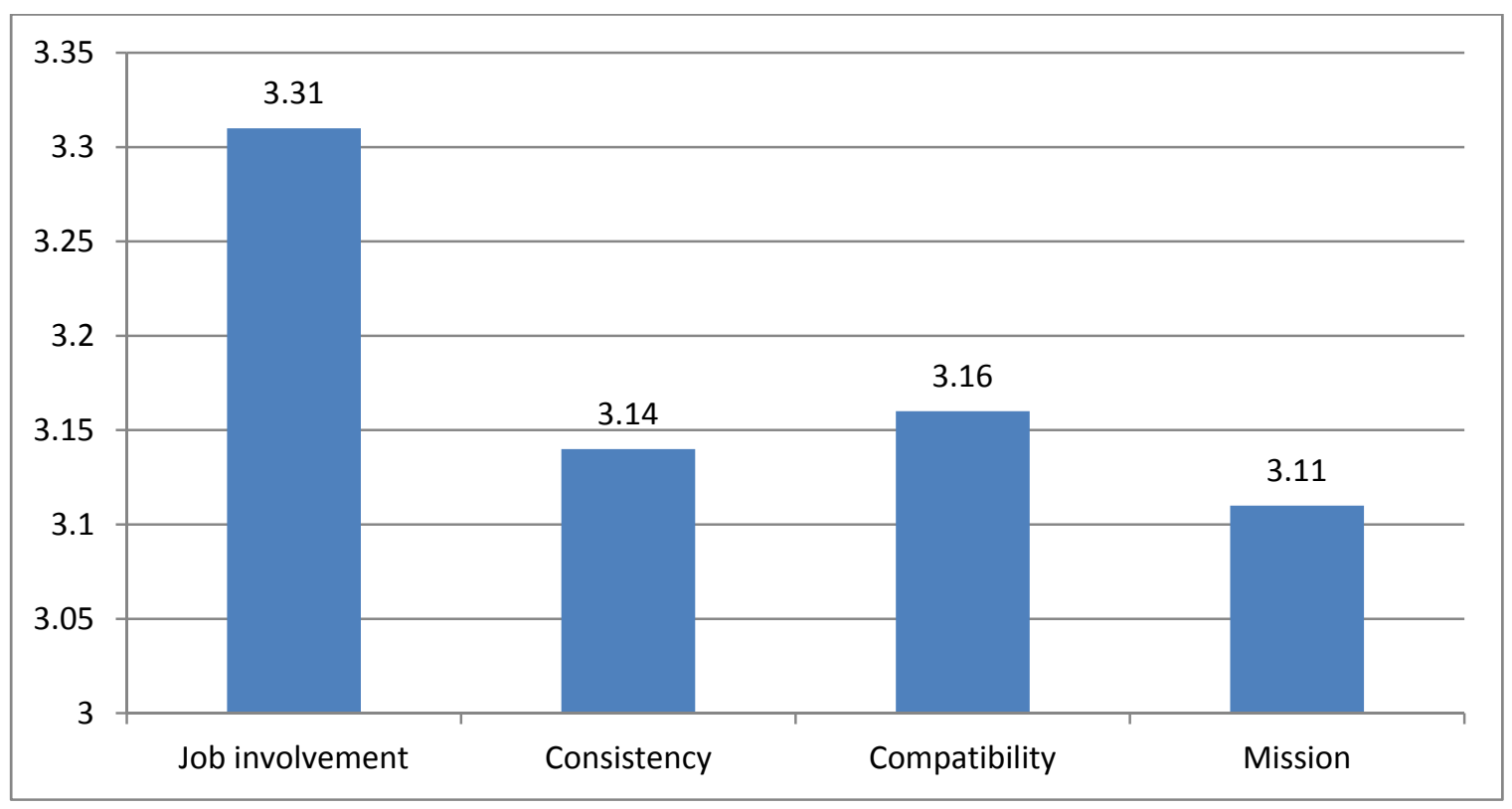

Fig. 2. Mean score of different components

In addition, Fig. 3 demonstrates the results of mean scores for three departments of consulting, education and support. As we can observe from the results of Fig. 2, job involvement is number one important factor followed by compatibility, consistency and mission. The study has accomplished in three different departments including consulting, consistency and support. Job involvement, in our survey, appears to gain the highest scores in consulting and education departments while consistency and compatibility have received the highest scores in support and education departments. Table 1 and Fig. 4 present details of the scores given to each sub-component of the survey.

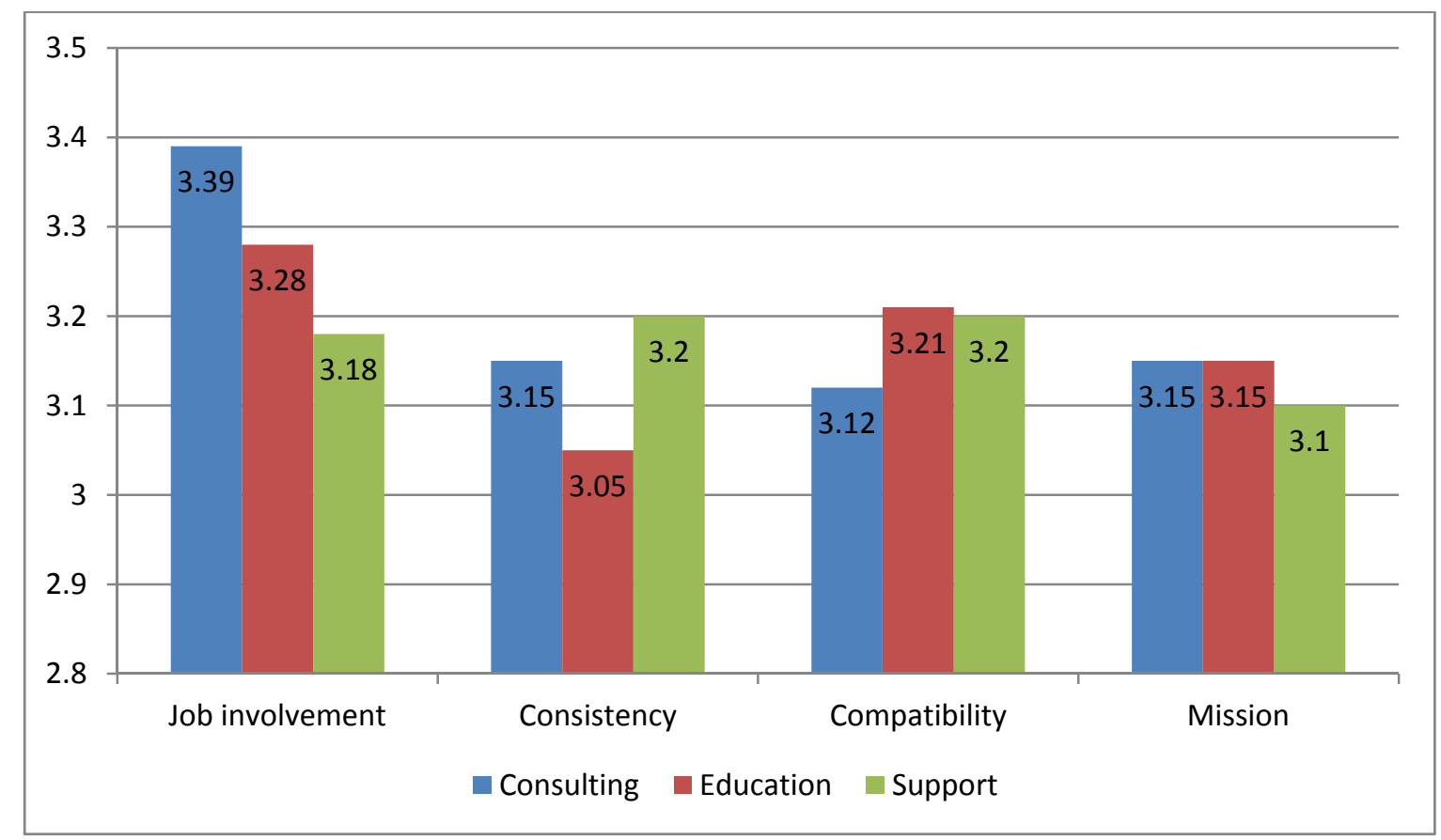

Fig. 2. Mean scores for different components of Denison model 
Table 1

The summary of the weights given to each sub-component of Denison model

\begin{tabular}{llccc}
\hline Main component & Attribute & Consulting & Education & Support \\
\hline \multirow{3}{*}{ Job involvement } & Empowering & 3.41 & 3.37 & 3.15 \\
& Team orientation & 3.15 & 3.13 & 3.05 \\
& Capacity development & 3.64 & 3.28 & 3.28 \\
\hline \multirow{3}{*}{ Consistency } & Core values & 3.31 & 3.15 & 3.28 \\
& Agreement & 3.32 & 3.03 & 3.33 \\
& Coordination and integration & 3.62 & 2.68 & 2.55 \\
\hline \multirow{3}{*}{ Compatibility } & Creating change & 3.06 & 3.12 & 3.17 \\
& Customer focus & 2.89 & 3.37 & 3.14 \\
& Organizational learning & 3.43 & 3.16 & 3.31 \\
\hline \multirow{3}{*}{ Mission } & Strategic direction and intend & 3.62 & 3.31 & 3.23 \\
& Goals and objectives & 2.85 & 3.90 & 2.94 \\
& Vision & 2.98 & 2.97 & 3.13 \\
\hline
\end{tabular}

According to the results of Table 1, job involvement includes three attributes of empowering, team orientation and capacity development and they are all within acceptable limits. Consistency is the second component of the survey, which is associated with three sub-components including coordination and integration, core values and agreement. The scores assigned to these components are also within acceptable limits. The third item, compatibility, also consists of three sub-components including creating change, customer focus and organizational learning and they are within acceptable limits. Finally, the last item, mission, includes three attributes including strategic direction and intend, goals and objectives and vision they are within acceptable level. There appears to be not much difference between internal and external affairs in our investigation. Therefore, we may conclude that the firm has devoted sufficient attention to both internal as well as external affairs.

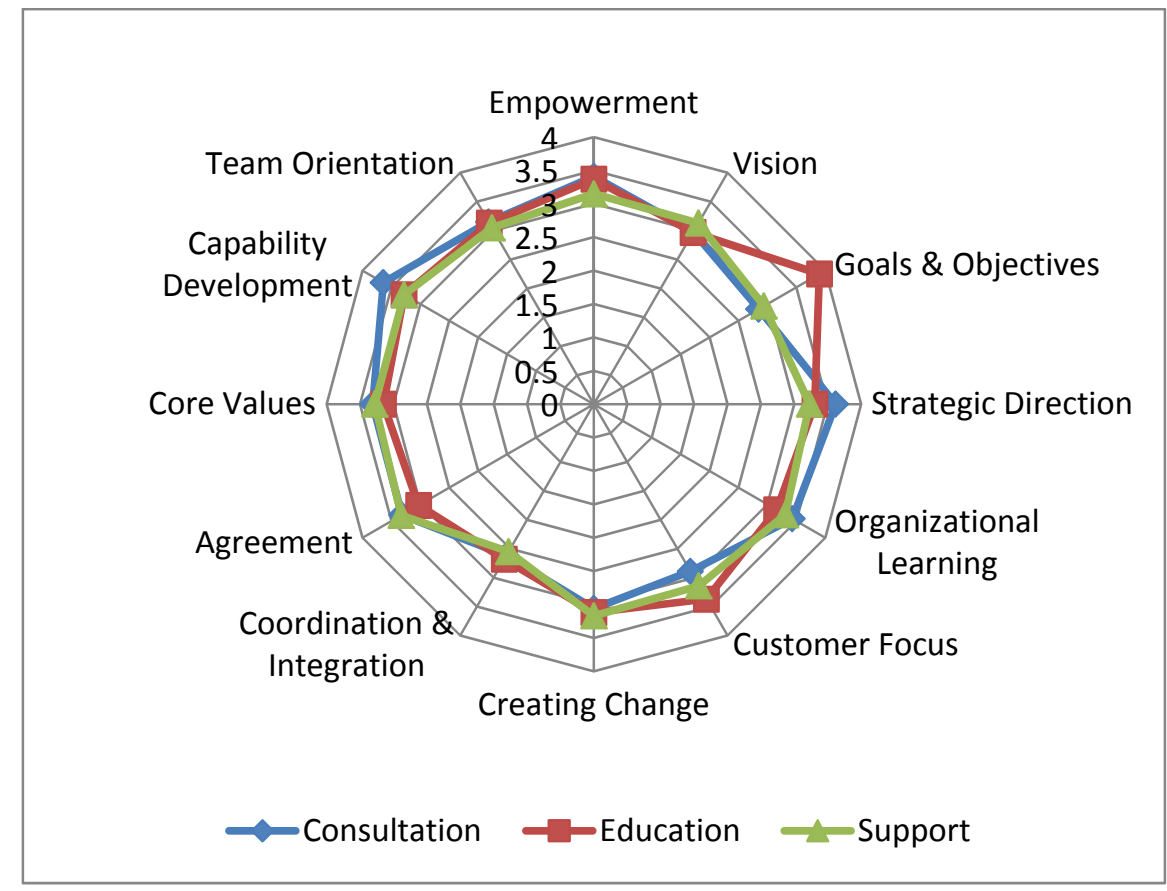

Fig. 4. The results of scores assigned to each component of the survey

As we can see from the results of Fig 4, there seems to be a good correlation among different components of the questionnaire. 


\section{Conclusion}

In this paper, we have presented study to determine important factors influencing organizational culture in food industry. The proposed study has adapted a questionnaire based on Denison organizational culture dimensions and distributed it among different groups of employees who worked for one of Iranian food maker in city of Zahedan, Iran. The results indicate that dimensions of job involvement (3.31) and organizational compatibility (3.16) are in better position compared with dimensions of consistency (3.14) and mission (3.11). We did not find any significance difference between in internal-external focus. In other words, the organization has paid sufficient attention to internal as well as external affairs.

\section{References}

Ashkanasy, N. M., Wilderom, C. P., \& Peterson, M. F. (Eds.). (2000). Handbook of organizational culture and climate. Sage.

Barbosa, Í., \& Cabral-Cardoso, C. (2007). Managing diversity in academic organizations: a challenge to organizational culture. Women in Management Review, 22(4), 274-288.

Denison, D. R., \& Mishra, A. K. (1995). Toward a theory of organizational culture and effectiveness. Organization science, 6(2), 204-223.

Denison, D. R. (1996). What is the difference between organizational culture and organizational climate? A native's point of view on a decade of paradigm wars. Academy of management review, 21(3), 619-654.

Denison, D. R. (2000). Organizational culture: Can it be a key lever for driving organizational change. The international handbook of organizational culture and climate, 347-372.

Denison, D. R., Janovics, J., Young, J., \& Cho, H. J. (2006). Diagnosing organizational cultures: Validating a model and method. Documento de trabajo. Denison Consulting Group.

Henri, J. F. (2006). Organizational culture and performance measurement systems. Accounting, organizations and society, 31(1), 77-103.

Jofreh, M., \& Masoumi, E.S. (2013). Diagnosing organizational culture: An empirical investigation. Management Science Letters, 3(9), 2461-2466.

Kia, S., Danaei, A \& Oroei, M. (2013). A study on relationship between knowledge management and organizational culture based on Denison model: A case study of PVC industry. Management Science Letters, 3(6), 1571-1574.

Kinicki, A., \& Kreitner, R. (2006). Organizational behavior: Key concepts, skills \& best practices. McGraw-Hill/Irwin.

Kwantes, C. T., \& Boglarsky, C. A. (2007). Perceptions of organizational culture, leadership effectiveness and personal effectiveness across six countries. Journal of International Management, 13(2), 204-230.

Mobley, W. H., Wang, L., \& Fang, K. (2005). Organizational culture: measuring and developing it in your organization. Harvard Business Review China, 3, 128-139.

Philip, G., \& McKeown, I. (2004). Business transformation and organizational culture:: The role of competency, IS and TQM. European Management Journal, 22(6), 624-636.

Tsui, A. S., Zhang, Z. X., Wang, H., Xin, K. R., \& Wu, J. B. (2006). Unpacking the relationship between CEO leadership behavior and organizational culture. The Leadership Quarterly, 17(2), 113-137.

Yilmaz, C., \& Ergun, E. (2008). Organizational culture and firm effectiveness: An examination of relative effects of culture traits and the balanced culture hypothesis in an emerging economy. Journal of World Business, 43(3), 290-306. 